\title{
柔軟な弾性表面を持つ円筒に働く流体力と周りの流れ場*
}

\author{
中田雅 子*1, 大 場 謙 吉*2
}

\section{Drag and Flow Field around Elasto-Flexible Cylinder in Uniform Flow}

\author{
Masako NAKATA and Kenkichi OHBA
}

\begin{abstract}
The purpose of this experiment is to clarify the mechanism of drag reduction in the natural swimming of fish, whales and dolphins. It is well known that the change in their shape and the local deformation of their skin contribute to drag reduction, especially in the case of dolphins. Therefore, in order to understand the interaction between a deformable surface and the local flow pattern, RFFRC (rigid front flexible rear cylinder) models of a simplified marine animal were studied in a water tunnel. The laser light sheet method was used to visualize the flow field around the models. The vortex pair shedding period from the models, the deformation of the models' cross-sectional form and models' drag were measured simultaneously. The following results were obtained. For some types of RFFRC which could be deformed easily in response to a change in the local flow pattern with vortex shedding, the increase in flow velocity in the wake was observed. In the case the St number was about 20\% higher than that of a rigid cylinder. Although, the drag that some types of RFFRC had was higher than that of the rigid one. However, the other types of RFFRC which could not quickly deform show no difference in St number, whereas the mean drag of this type was about $20 \%$ lower and the time variation of the drag became smaller than that of the rigid cylinder.
\end{abstract}

Key Words: Vortex, Separation, Flow Visualization, Bio-Fluid Mechanics, Flexible Surface, Hydrodynamical Drag

\section{1. 緒言}

動物は，それぞれの生活様式にあった都合のよい身 体の形状と運動方法をもっている.これらの形状と運 動方法は既存の人工構造物と比べると大変優れた面が ある. 流体力学的な観点から見ると, とりわけ水中に 生活基盤をおく動物達(特に, 魚・イルカ・鯨類など) は陸上の動物と比べ形状は流線形で, 運動効率もよ い(1). それゆえ，これらの形状および運動機構を理解 することは工学の発展に扔いて極めて有意義なことと 思われ，それらを解明するための研究がいろいろな分 野にわたって行われてきた(2).しかし，生体特有のさ まざまな要因が絡み合っているために，機構すべての 解明には至って扔らず, 現段階では生体の機能のある 部分に着目した研究にとどまっている.

本研究では, 特に魚鯨類の形状が流れに応じて変形 し得ること,また特にイルカに扔いては，皮膚の一部 が局所的に変形することが抵抗軽減に寄与していると 言われていることから (3)(4), その因果関係を流体力学 的な観点から解明するために，流れ場に応じて容易に

* 原稿受付 1996 年 7 月 12 日.

*1 准員, 関西大学大学院 (画 564 吹田市山手町 3-3-35).

*2 讵員, 関西大学工学部.
変形する, 柔軟な弾性表面をもつモデルを用い, 表面 が変形することと物体自身の受ける流体力および周り の流れ場との関係について調べた，本報では，柔軟な 弾性膜を持つ円筒モデルと剛体円筒モデルとの間に, はく離点の位置, はく離渦の大きさや放出周期, 後流 のようす，抗力においてどのような違いが見られたか について報告する。

\section{記 号}

$$
\begin{aligned}
x, y & : \text { 主流, 鉛直方向の座標 } \mathrm{m} \\
U_{\infty} & : \text { 主流速度 } \mathrm{m} / \mathrm{s} \\
\bar{U}_{(y)} & : \text { 後流中の流速の時間平均値 } \mathrm{m} / \mathrm{s} \\
d & : \text { モデル直径 } \mathrm{m} \\
f & : \text { :く離渦対の放出周波数 } \mathrm{Hz} \\
R e & : \text { モデル直径に関するレイノルズ数 }\left(=U_{\infty} d / \nu\right) \\
S t & : \text { はく離渦対の放出周波数に関するストロー八 } \\
& \text { ル数 }\left(=f d / U_{\infty}\right) \\
D_{M L} & : \text { 後流の運動量損失より求めた抗力值 } \mathrm{N} \\
\bar{D} & : \text { 抗力の時間平均值 } \mathrm{N} \\
\bar{D}_{\mathrm{RC}} & : \text { 基準剛体円筒の抗力の時間平均值 } \mathrm{N}
\end{aligned}
$$

\section{2. 実験装置および方法}

$2 \cdot 1$ 実験装置 本実験で用いた奏験装置の概略 
を図 1 に示す．回流水槽は長さ約 $2.5 \mathrm{~m}$, 高さ約 1.0 $\mathrm{m}$, 幅約 $0.5 \mathrm{~m}$ の大きさであり, 幅 $200 \times$ 高さ $200 \times$ 長さ $700 \mathrm{~mm}$ のアクリル製测定部をもち, 上面のふた によって密閉水路となる. 水流は回流水槽下部に設置 してあるインペラで発生させ, 約 $0.3 \mathrm{t}$ の水を最大流 速 $3.0 \mathrm{~m} / \mathrm{s} て ゙$ 流すことができる．測定区間では整流 板を経てほぼ一様な流れが実現しており，今回実験に 使用した流速域では Re 数に対するフローパターンの 変化はない。また，モデルは測定部に流れに垂直にな るようにして水平に設置した。本実験での主流速度 は，モデル直径を基準としたレイノルズ数 $\operatorname{Re}(=$ $\left.U_{\infty} d / \nu\right)$ 域が約 $3.0 \times 10^{3} \sim 2.0 \times 10^{4}$ になるように約 0.1 $\sim 0.6 \mathrm{~m} / \mathrm{s}$ の範囲で変化させた.

$2 \cdot 2$ 供試モデル 供試モデルを図 2 に示す. 図 2 (a)には 3 夕イプの基本形状モデルを示した。基本 形状は主にモデルのもつ剛体部分の角度 $\theta$ に関して, $0^{\circ}, 360^{\circ}, 0<\theta<360^{\circ}$ と三つに分けたモデルであり， $\theta$ $=360^{\circ}$ は従来の理論と比較するために用いた岡体円 筒 (以下 RC), $\theta=0^{\circ}$ は断面がすべて柔軟弾性膜面 の みで形成されている柔軟弾性円筒(WFC), $0<\theta<$ $360^{\circ}$ は, 水中の動物が水流の全圧を受ける頭部は硬 く, 静圧を受ける後部は柔らかい身体の構造を持って いることを模擬するため作成した，流れに対して前面 が剛体, 後面が弾性膜からなる複合円筒 (RFFRC)で ある.さらに柔軟な弾性壁面をもつモデルの流れ場に 対する応答性を変えるパラメータとして, 膜厚 $t(t=$ $0.03 \mathrm{~mm}$ : Latex Rubber(ヤング率 $E=2.0 \times 10^{6} \sim 4.0$ $\left.\times 10^{6} \mathrm{~Pa}\right), t=1.0 \mathrm{~mm}:$ Natural Rubber), モデルの 状態(流れ場とモデル内部の液体が出入りできる開放 形：O, 流れ場とモデル内部の液体の出入りがない密 閉形：C), RFFRC モデルについては図 2(b)に示す 前面剛体部の角度 $\theta\left(\theta=90^{\circ}, 135^{\circ}, 180^{\circ}, 270^{\circ}\right)$ また, 密 開形のモデルについては，容積率 $V^{\prime}$ (ゴム円筒がちょ

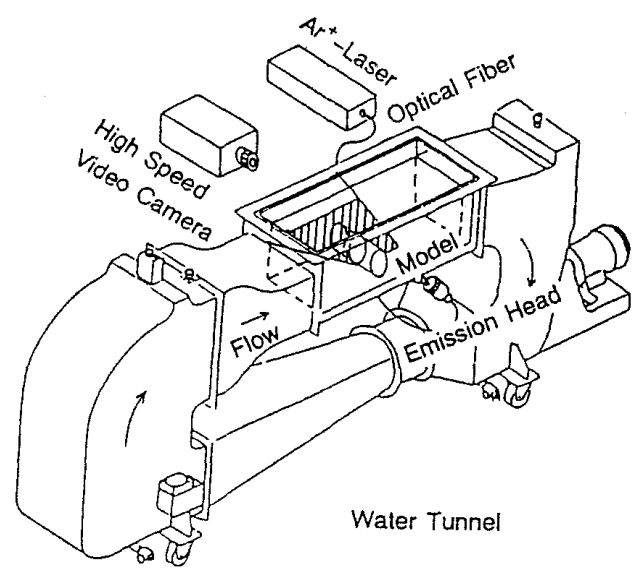

Fig. 1 Outline of experimental apparatus
うど張力零の状態で円形に膨らんだときの断面積に円 筒長さをかけたものを基準体積 $V_{0}$ とし，それに対す る実際の円筒容積 $V$ の比を容積率 $V^{\prime}$ と定義したと き, $\left.V^{\prime}=0.9,1.0,1.1\right)$, 加光て図 2(c)に示すように, 密閉時にモデル後部の変形振動によって誘起される内 部液体の振動を抑えるため,メッシュ状の紙を内筒状 に巻き，モデル中心に固定したディフューザ $D$ (あり， なし)を考えた。実験に際しては，得たい情報にあわ せて基本モデルに各パラメータを組合せて使用した。

$2 \cdot 3$ 流れの可視化 モデル付近の流れ場のよう すの観察には，流れ場にトレーサとして混入してある 平均粒径約 $290 \mu \mathrm{m}$ のポリエチレン粒子に $4 \mathrm{~W}$ のアル ゴンレーザをシート状に広げ，測定部下方より流れに 対して平行に照射することで流れ場を可視化するレー ザライトシート法を用いた，流れ場のようすはトレー サ粒子からの反射光を用いて側方より毎秒 250 駒の録 画・再生能力のある高速ビデオカメラで撮影され，得 られた可視化画像より, 後流へのはく離渦の放出パ夕 ーンに加え, モデルの表面の運動, モデル断面の変形 の解析を行った。また, 広範囲の流れ場の計測には $1000 \mathrm{~W}$ のハロゲンランプ光を $5 \mathrm{~mm}$ のスリットに 通した光を利用し, スチールカメラでも撮影を行った. さらに, はく離点近傍の流れの観察にはコンデンスミ ルク法を用いた。
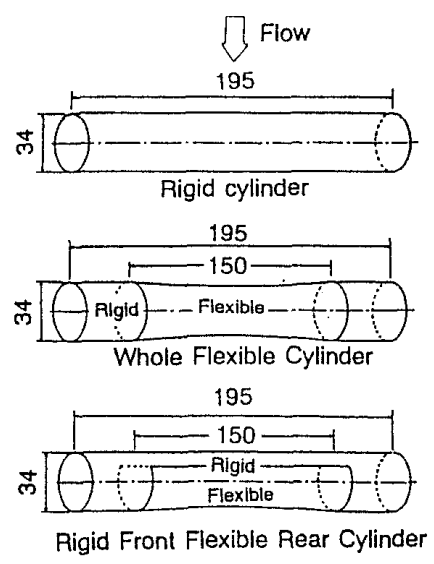

(a) Basic models

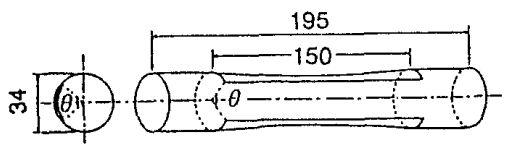

(b) Details of RFFRC

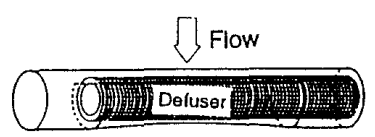

(c) Model with the defuser

Fig. 2 Models 


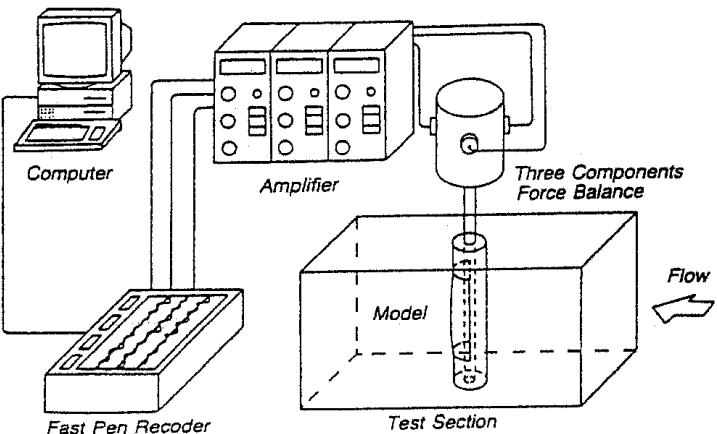

Fig. 3 Schematic diagram of drag measurement system

$2 \cdot 4$ 流体力の測定 柔軟な弾性壁を持つモデル と固体壁のモデルの受ける流体力を比較するため, 図 3 の計測装置を用いて直接測定を行った．流体力の測 定には，抗力，揚力，ピッチングモーメントを測定で きるストレインゲージ式の 3 分力検出器を用い, 高速 ペンレコーダおよびコンピュータを通して揚力, 抗力, モーメントについて記録し, 時間平均值と時間変動波 形を得た。本報では特に抗力について結果を示す。

\section{3. 実験結果および考察}

$3 \cdot 1$ 柔軟な弾性表面が流れ場に及ぼす影響周 長に占める柔軟な弾性膜面の割合による流れ場の相違 をみるために，基本形状モデルを用いて流れ場を可視 化し，粒子追跡法によって後流における流速の時間平 均值の分布を求めた。 その結果を図 4 に示す。膜面の 影響をより見やすくするために，応答性のよい開放形 モデルで実験を行った，RFFRC モデルについては $\theta$ $=135^{\circ}$ 使用した。また図中の $a-a, b-b, c-c$ 面は それぞれモデルの中心位置を原点として $, x=2 d, 4 d$, $6 d$ の位置である. 図 4 より, $\theta=0^{\circ}$ の FC-O は流れ に対する前面が流れの全圧によってつぶされ，前面が フラットな半円状断面となり，流れは平坦な前面の端 ではく離しており，しかもモデル全体がたわんだ状態 で振動していたため, 後流の運動量損失も RCに比べ てはるかに大きくなっていた。この状態においては, モデル表面の膜面には，かなりの張力がかかっている と考方られ，膜面の柔軟性は失われていると考えられ る.

それに対して $\theta=135^{\circ}$ の RFFRC-C は流れの全压 によって前面がつぶされることがないため, 断面後部 の柔軟な弾性壁面ははく離渦の放出に伴って変形し振 動した. 後流の幅も RCに比べて狭くなっており, 放 出されたはく離渦の大きさも小きく, 後流の流速も早 くなっていた。これらのことから，柔軟な弾性壁面を もつモデルのうちで, 前面が硬くて流れのはく離が起

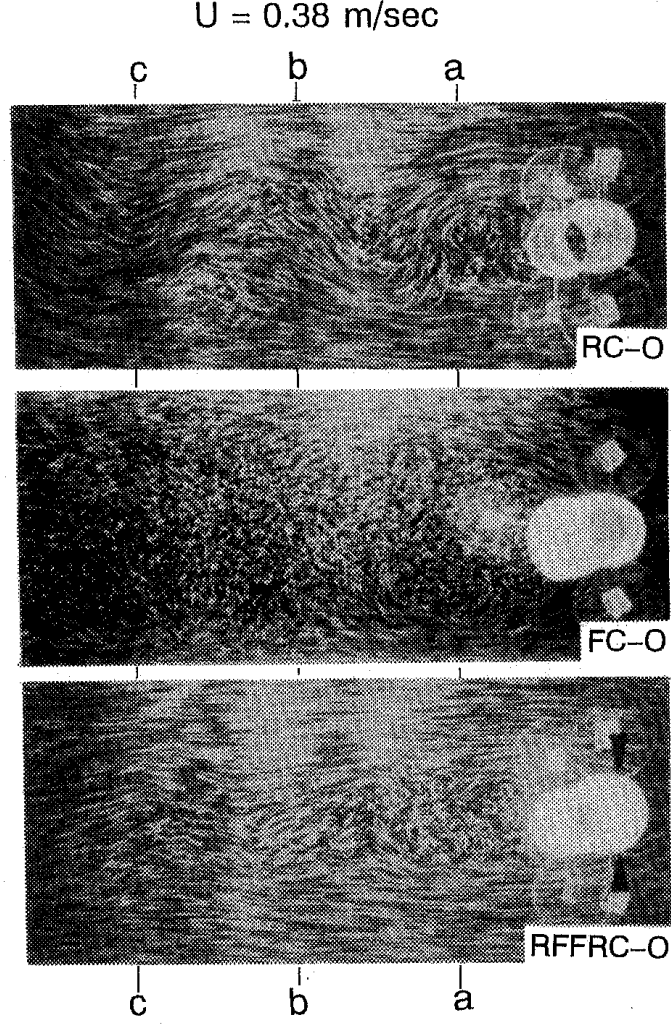

(a) Visualization of the flow pattern

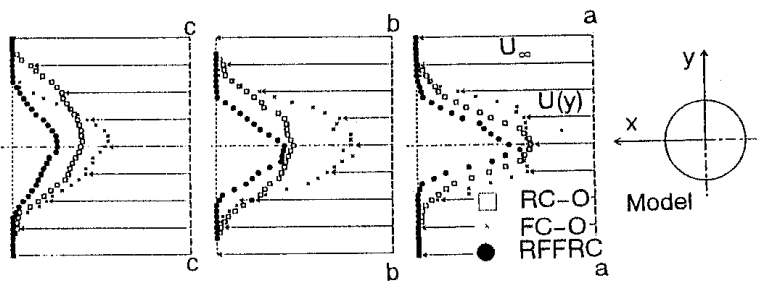

(b) Velocity distribution in the wake

Fig. 4 Flow pattern in the wake of basic models

こりにくい形状を保っており，はく離点付近の壁面が 流れ場の変動に応じて容易に変形できるようなモデル が, 流れ場との間で相互作用を引き起こすことができ， 抵抗減少につながるのではないかと推察される。

$3 \cdot 2$ 各パラメータがストローハル数や断面形状に 及ぼす影響＼cjkstart本節では RFFRCモデルについて各 パラメータを変化させた場合のはく離渦対の放出に関 するストローハル数とはく離渦放出時の断面形状を調 べることによって考察を行う。

図 5 に各パラメータを変化させたときのレイノルズ 数に対するストローハル数 $S t\left(=f d / U_{\infty}\right)$ の値を示す.

図中の実線は渦対の放出周波数に対する Taylor の 実験式

$$
f=0.198 \frac{U_{\infty}}{d}\left(1-\frac{19.7}{R e}\right)
$$


より求めたストローハル数である.ここでは主に $t=$ $0.03 \mathrm{~mm}$ のモデルについて示し,$t=1.0 \mathrm{~mm}$ のモデル についてはパラメータを変えてもほとんど変化が見ら れなかったため, RFFRC-O モデルについてのみ結果 を示した。

図 5 の (a)〜 (d) は, 各モデルのRe 数に対するス トローハル数が 4 種類の傾向を示したので, その傾向 別にそれぞれ Pattern a, Pattern b, Pattern c, Pat tern d に分けたものである。また，図 6 に断面形状の 可視化写真とはく離渦放出時のスケッチを示したが, 図 5 で分類した各パターンのモデルははく離渦の放出 時の断面形状についても同じような特幑を持っていた ため, 同様に分類した. 各パターンのストローハル数 と断面形状に関する特徵・属するモデルは以下に示 于.

Pattern a：このパターンに分類されるモデルは, レイノルズ数を変化させても, $\mathrm{RC}$ モデルと比較して ストローハル数や断面形状にほとんど違いが見られな かった.ここに属するモデルは $t=0.03 \mathrm{~mm}$ の RFFRC-O-180 (複合円筒モデル・開放形・剛体部 $180^{\circ}$, 以下同様), O-270, $t=1 \mathrm{~mm}$ の-90である. この原因としては, $t=0.03 \mathrm{~mm}$ のモデルでは, $\theta=$ $180^{\circ}$ を超えたため柔軟な弾性膜面の可動域が制限さ

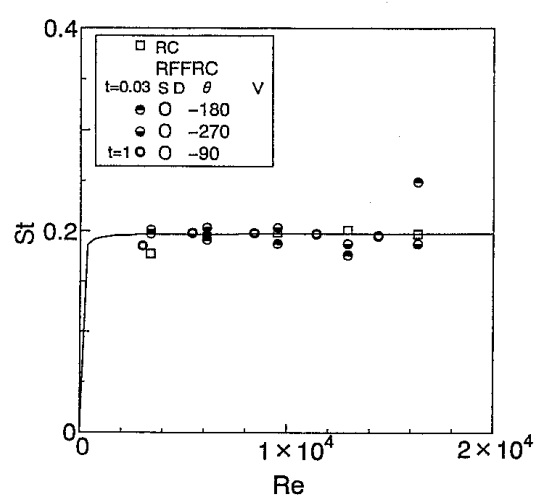

(a) Pattern a

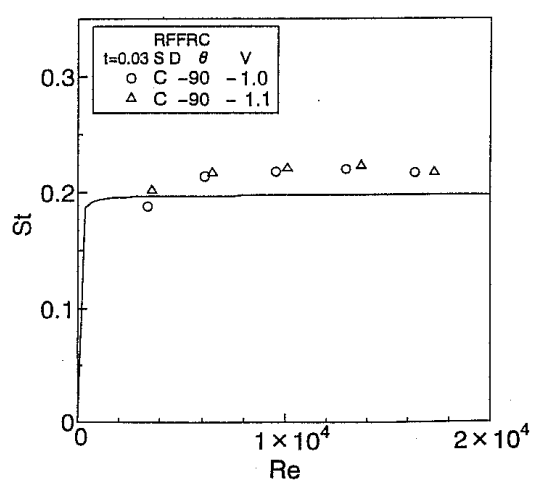

(c) Pattern c
れたことに加え，はく離点付近の壁面が固体壁である こと, また $t=1 \mathrm{~mm}$ のモ゙ルでは柔軟な弾性膜面の 可動域は大きいが膜の肉厚が厚いことにより, 流れ場 の変化に対して鈍くなったと推測される.

このパターンでは，柔軟な弾性壁面をもちながらも， 流れ場およびモデル自身に活とんど壁面の柔軟性の影 響が見られないため， RCモデルと同等に扱うことと し，以後考察からは省くことにする。

Pattern b:このパターンに分類されるモデルは, ストローハル数がレイノルズ数約 $1.0 \times 10^{4}$ 辺りから 急に上昇し，断面形状がこのレイノルズ数辺りからは く離渦の放出に伴って図 6(b)に見られるような局所 的な変形を行った。ここに属するモデルは O-90, O135, C-90-0.9 (密䦤形・剛体部 $90^{\circ}$ ・容積率 0.9 , 以下 同様)である。

この局所的な変形の要因としては，これらのモデル においてはく離点近傍の壁面が柔軟な壁面であり，さ らに他のモデルに比べて膜面の束縛力が小さいため, はく離渦の放出に伴う流れ場の圧力変化により変形が 生じると考えられる。

さらにこのパターンの変形を行うと, はく離渦の放 出時に流れ場から供給されるエネルギーが一部モデル の壁面を膨らませるのに使われ，渦が RCに比べて小

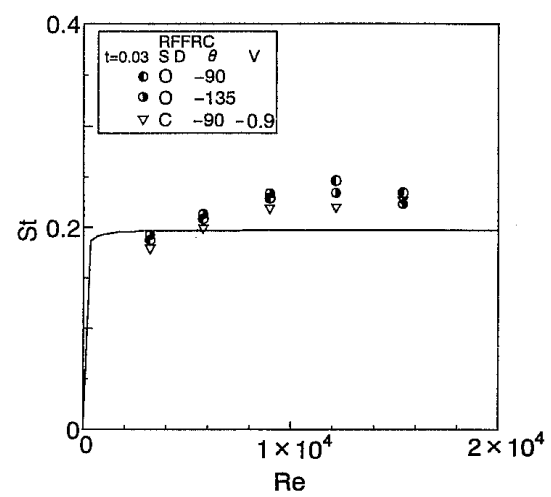

(b) Pattern b

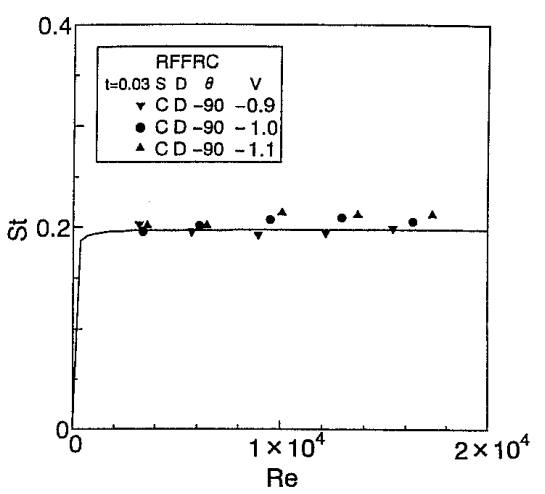

(d) Pattern d

Fig. 5 St-number versus $R e$-number 


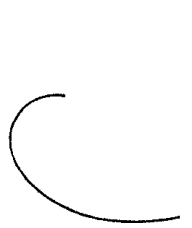

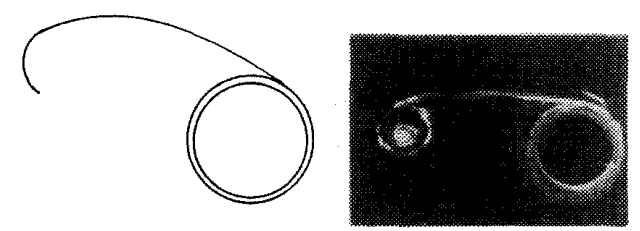

(a) Pattern a (RC)

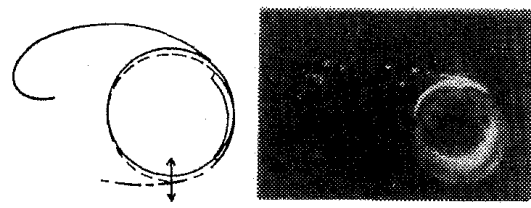

(c) Pattern c (RFFRC-C-90-1.0)

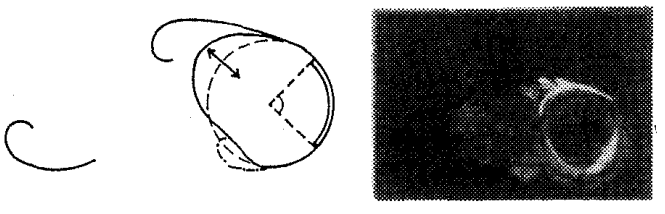

(b) Pattern b (RFFRC-O-90)

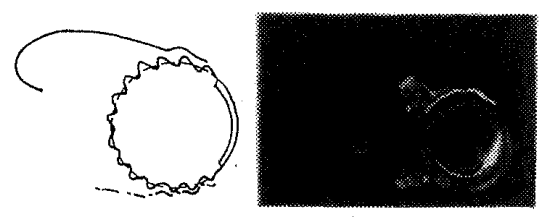

(d) Pattern d (RFFRC-C-90-0.9)

Fig. 6 Cross sectional form and sketch of vortex shedding patterns

さい状態で放出される。これによって図 4 に見られた ような流れ場になったと考えられる。そのメカニズム としては，生成された渦による圧力低下に伴って膜面 が渦中心に向かって膨らみ, 図6(b)に見られるよう に断面の反対側の膜面の山みという弾性変形を生みだ し，この凹み動作時に周囲の流れを吸込み，新しい渦 を誘起していたことから，この渦放出メカニズム(5)が $\mathrm{RC}$ はく離渦生成のメカニズムに加わることにより， ストローハル数を増加させたと考えられる。

Pattern $\mathrm{c}$ ：このパターンに分類されるモデルは, ストローハル数の上昇は Pattern bよりも速い段階で 見られるが，あまり高い値は示さなかった．また，断 面の変形もほとんど見られなかった，ここに属するの は，密閉形モデルの中でも容積率 $V^{\prime}$ が 1.0 を超える C-90-1.0とC-90-1.1のモデルである.

これらのモデルは柔軟な弾性壁面が内圧の影響を強 く受けるため，断面形状は円形を保っているが，モデ ル全体的には弾性体であるためレイノルズ数が $6 \times$ $10^{3}$ を超えるあたりから，モデル自体の上下振動が見 られた.この上下振動が起こり始める辺りからストロ 一八ル数が上昇している.この振動周期は渦の放出周 期と一致していたが，同じ渦対形状をしている RCに 比べると周期が短い．また，渦対の放出位置がモデル に近づいていたことからこのパターンでは内部液体 の慣性による振動が渦の発生に強い影響を与えていた と考えられる。

Pattern d：このパターンに属するモデルは内部に ディフューザをもつ CD-90-0.9(密閉形・ディフュー ザあり・剛体部 $90^{\circ}$ ・容積率 0.9 , 以下同様) CD-901.0, CD-90-1.1である. ストローハル数に関しては Pattern a と同じく $\mathrm{RC}$ とあまり違いが見られないが, 柔軟な弾性壁面には図6(d)に示すような, $d / 10 〜$ $d / 20$ の波高を持ったはく離渦の発生とは同期してい ない進行波が観察された。この進行波はディフューザ があるため渦の放出に伴う流れ場の変動に内部液体が 応答できず遅れが生じたため, 柔軟弾性膜面のみが変 形することができたために発生したと推測される。

以上のことから，流れ場やはく離渦の放出に影響を 与える重要な要因は，はく離点付近の壁面の流れ場に 対する応答性と考えられる，応答性が極めてよいと， 受動的な変形であるにも関わらず, 流れ場に対するモ デル自体の影響を減少させられる，すなわち抵抗減少 につながることが明らかになった。

$3 \cdot 3$ モデルの受ける流体力 $\quad 3 \cdot 1,3 \cdot 2$ 節に抒い て, RFFRCモデルのうち応答性を高めたモデルは, 後流の運動量損失が減少することを示したが, 後流中 の運動量損失の減少は剛な物体については，モデルの 受ける抗力 $D_{M L}$ がピトー・トラバース法により，

$$
D_{M L}=\int_{-\infty}^{+\infty} \rho U_{(y)}\left(U_{\infty}-U_{(y)}\right) d y
$$

のように運動量損失を用いて表されることから，モデ ルの受ける抗力の減少を意味することになる。そこで 実際に測定した流体力，とくに抗力について時間平均 値,および時間変動波形について考察し，モデルの壁 面の応答性との関係について考察する。

図 7 に各モデルの抗力の時間平均値 $\bar{D}$ を $\mathrm{RC} テ ゙$ ルの抗力值 $\bar{D}_{\mathrm{RC}}$ との差で表した值と後流の $x=4 d に$ おいての運動量損失より求めたおの扔のの計算值 $D_{M L}-D_{\mathrm{RC}}$ を示す。この結果より，柔軟な弾性表面を もつ各モデルも抗力値は後流の運動量損失より求める 值とは必ずしも一致しないということが明らかになっ た.さらに $3 \cdot 2$ 節で分類したPattern bにおいては, 変形の傾向は同じでも抗力の傾向は，一方は減少，一 方は増加の傾向を示し，一致しなかった。しかし，こ 


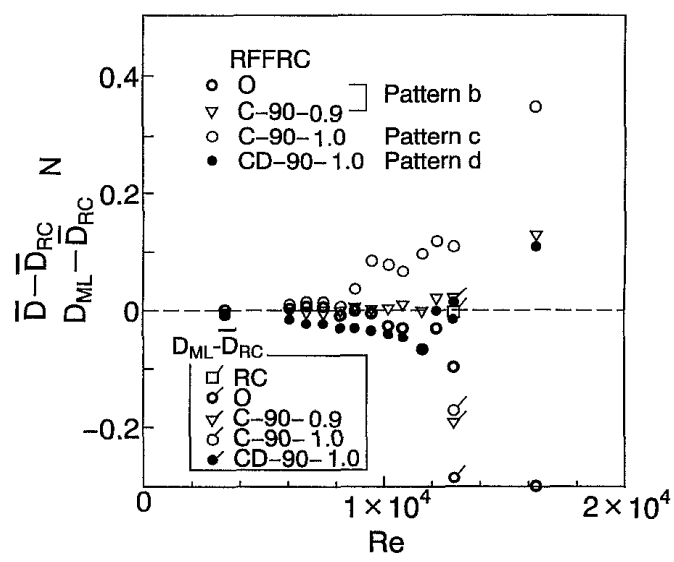

Fig. 7 The mean value of drag and drag calculated by momentum loss

の Pattern b の RFFRC-O モデルはモデルと流机場 の間に流体の出入りがあるため, 他のモデルや RC の 抵抗值と直接比較を行えないため抵抗值が減少してい るとは言いがたい.一方, RFFRC-C-90-0.9 の抗力 值はPattern c と同じ傾向を示していた。また, 流れ 場の変化がほとんど見られなかったPattern d のモデ ルは，ディフューザの効果が薄れる $\operatorname{Re}$ 数 $1.6 \times 10^{4}$ を 超えるまでRCよりも抗力は低かった。

これらのことから，モデルの受ける抗力の時間平均 值の傾向は, 流机場の大きな変化や断面形状の大変形 には必ずしも依存していないと考元られる。

この原因を考元るために，抗力の増加したモデルと 減少したモデルについて抗力の時間変動波形の比較を 行った. 図 8（a）には基本波形として， RCモデルと 流れ場の影響が減少していた RFFRC-O モデルの抗 力の時間変動波形を, 図 8(b)には図7で見られた抗 力の時間平均値が増加傾向をとったモデルと減少傾向 をとったモデルに対するそれぞれの時間変動波形を示 した。この図より，ディフューザのあるモデルは開放 形の波形に近く，ほとんど振動が見られないのに対し て, ディフューザのないモデルは RCよりもはるかに 大きな渦の放出周期と一致した周期を持つ幅の広い振 動波形が現れていた。

このことから, 抗力の増加の原因としてモデル内部 の液体の慣性力の成分が抗力に付加されたことが考え られる。

さらに Pattern d の表面の微小変形自体が抗力軽減 に関係していると考元られることから，イルカの遊泳 中に観察される抵抗軽減のための微小進行波との関連 性も推測され，今後さらなる解析を行う必要があると 考えられる。
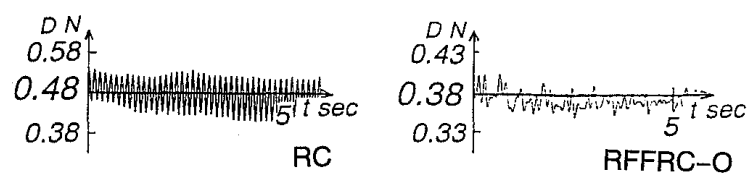

(a) Basic time variation patterns of drag
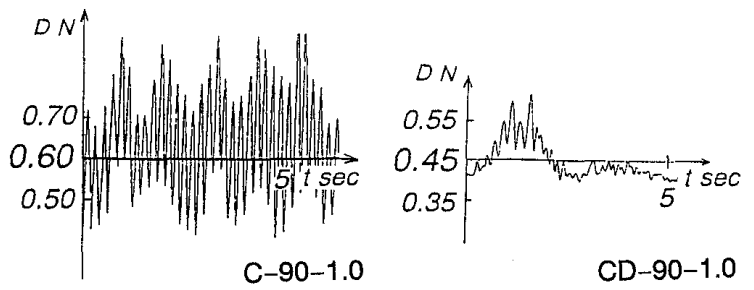

(b) Two time variation patterns

Fig. 8 Time variations of drag

\section{4. 結言}

柔軟な弾性表面をもつ円筒に働く流体力とその周り の流れ場について可視化実験と抗力の測定を行った結 果，以下のことが明らかになった。

（1）前面が剛で後部が柔の円筒モデルのはく離点 近傍の壁面が非常に柔軟で周囲の圧力変化に応じてか なり自由に変形できる場合, はく離渦の放出に伴う壁 面の変形により渦対の放出周波数が高まり, ストロー ハル数が剛円柱の場合より $20 〜 30 \%$ 高くなった。

（2）この前剛後柔円筒モデルでは, 剛円柱にくら べて流れのはく離点が $10 \sim 20^{\circ}$ 後流へ下り，したがっ て後流の幅が小さくなった。しかし，この後流幅の縮 小は抗力隇少に結びつく場合とそうでない場合とがあ った.

（3）密閉形前剛後柔円筒モデルの内部流体の流動 を円筒内部のディフューザにより妨げると, 円筒表面 に微小な進行波が発生し，このとき抗力の減少が見ら れた。

終わりに，本実験に協力して頂いた，当時の本学 4 年生の田地川 勉, 浜野洋次, 大谷敏雄, 香山和久, 藤 田浩史の諸氏に謝意を表する。

\section{文献}

(1) Lighthill, J., Mathematical Biofuiddynamics, (1975), 3, SIAM publications.

(2) 谷一郎, 科学, 34-9 (1964), 471-476.

(3) Kramer, M. O., J. Am. Soc. Naval. Engrs., 74(1960), 341348.

(4) Carpenter, P. W. and Garrad, A. D., J. Fluid. Mech., 155 (1985), 465-510.

(5) Nakata, M. and Ohba, K., J. Phys. Soc. Japan, 65 9 (1996), 3080-3081. 